\title{
O POSICIONAMENTO ESTRATÉGICO COMO DETERMINANTE DO FUTURO DE UMA INDÚSTRIA DE MÓVEIS: CASO DE ENSINO
}

\author{
C.C.Webber $^{1 *}$; F.P.Nunes ${ }^{1}$ e J.C.F.Guimarães ${ }^{1}$ \\ 1 Faculdade Meridional - IMED, 99070-220, Passo Fundo- RS, Brasil \\ *clebercw@hotmail.com
}

\section{RESUMO}

O presente caso apresenta um momento decisivo na trajetória da empresa Expolight, uma empresa familiar que está a vários anos no mercado atuando no segmento de móveis comerciais. Localizada no estado do Rio Grande do Sul, que é um dos principais polos moveleiros do Brasil, sendo os produtos desta região reconhecidos por sua elevada qualidade. O caso apresenta um ponto de decisão onde a empresa precisa optar entre manter sua posição no mercado, ou aceitar o desafio de um novo cliente, levando em consideração os investimentos e riscos envolvidos. O objetivo deste Caso de Ensino é promover discussões e reflexões sobre temas como empreendedorismo, administração estratégica, gestão da inovação e Marketing, exercitando a tomada de decisão com base nos dados apresentados. Também possui elemento para o debate sobre globalização, parcerias e cultura organizacional.

PALAVRAS-CHAVE: Empreendedorismo, Inovação, Administração estratégica, Marketing.

\section{THE STRATEGIC POSITIONING AS DETERMINING OF THE FUTURE OF A FURNITURE INDUSTRY: EDUCATION CASE}

\begin{abstract}
This case presents a turning-point in the history of the company Expolight, a family company that is several years in the market working in the commercial furniture segment. In the state of Rio Grande do Sul, which is one of the leading furniture manufacturers poles of Brazil, being the products of this region recognized for their high quality. The case presents a decision point where the company needs to choose between keeping their market position, or accept the challenge of a new client,
\end{abstract}

taking into consideration the investments and risks involved. The purpose of this Educational Case is to promote discussion and reflection on topics such as entrepreneurship, strategic management, innovation management and marketing, exercising decision-making based on the data presented. It also has element to the debate on globalization, partnerships and organizational culture.

KEYWORDS: Entrepreneurship, Innovation, Strategic management, Marketing. 


\section{INTRODUÇÃO}

O estado do Rio Grande do Sul é um dos principais polos moveleiros do Brasil, sendo reconhecido pela elevada qualidade dos produtos, fabricados por grandes empresas com renome internacional, e também por pequenas e médias empresas que oferecem produtos diferenciados para os diversos tipos de consumidores

A Associação das Indústrias de Móveis do Rio Grande do Sul (MOVERGS, 2012) demonstra que, no Rio Grande do Sul, existem 2,7 mil indústrias moveleiras, das quais $86 \%$ produzem móveis de madeira, $8 \%$ móveis de metal, cerca de 5\% móveis estofados e $1 \%$ outros móveis. O setor de móveis gaúcho é composto principalmente por pequenas e médias empresas: cerca de $42 \%$ faturam até R $\$ 600$ mil/mês; $16 \%$ faturam de R \$ 601 mil a R \$ 1,2 milhões; $32 \%$ faturam de $\mathrm{R} \$ 1,2$ a $\mathrm{R} \$ 5,0$ milhões; e apenas $10 \%$ faturam acima de $\mathrm{R}$ \$ 5,0 milhões/mês. No Rio Grande do Sul, o setor moveleiro emprega aproximadamente 39 mil pessoas.

Nesse contexto, encontra-se a Expolight expositores, uma empresa que produz móveis comerciais (equipamentos para lojas como balcões, prateleiras, gôndolas), entre outros. Trata-se de uma empresa familiar, fundada em 1998, mas que traz a experiência adquirida em outras empresas da família, que atua neste ramo desde 1976. A empresa fabrica móveis em metal e em MDF e nos últimos anos tem buscado constante atualização de seus produtos, bem como atingir novos mercados e clientes.

O presente Caso de Ensino tem como objetivo promover discussões e reflexões sobre temas como empreendedorismo, administração estratégica, gestão da inovação e Marketing, exercitando a tomada de decisão, utilizando o caso da empresa estudada e os conhecimentos apresentados na revisão bibliográfica. Os temas abordados podem ser aplicados em cursos de graduação e pósgraduação, contribuindo de forma significativa para a compreensão na prática das teorias estudadas, principalmente em relação a gestão e a tomada de decisão.

Para uma melhor compreensão, será desenvolvida uma revisão bibliográfica com os temas pertinentes ao Caso de Ensino, em seguida será apresentado o método e após o histórico da empresa, bem como suas características, o ponto de decisão e as recomendações para a utilização do caso.

\section{REVISÃO BIBLIOGRÁFICA}

Para embasar o estudo e as decisões a serem tomadas com base nas informações da empresa, bem como para auxiliar nos questionamentos que serão apresentados, segue um breve referencial teórico sobre os temas a serem estudados.

\subsection{Empreendedorismo}

Empreendedorismo não é somente o ato de abrir um novo negócio uma vez que para ser considerada como empreendedora a empresa precisa ter uma série de características especiais. Tão pouco, o termo empreendedorismo cabe somente a pequenas e novas empresas, grandes empresas tradicionais costumam ser reconhecidamente empreendedoras (DRUCKER, 2010).

A identificação de oportunidades é fator crucial para o empreendedorismo. Alguns fatores são importantes a serem avaliados, como o mercado, as vantagens competitivas e equipe gerencial (DORNELAS, 2005). Existe um consenso que outros fatores ajudam a criar o perfil empreendedor, que são a capacidade de assumir riscos, conhecimento sobre o ramo de negócio, organização, capacidade de tomada de decisão, definir objetivos, dinamismo e independência (SALIM, et al, 2004). 
A inovação e empreendedorismo estão intrinsecamente ligados e um dos elos que as une pode ser definido como a necessidade. Esta necessidade normalmente nasce da incongruência, ou seja, com um trabalho que precisa ser realizado. Muitas vezes a inovação ocorre com o conhecimento já existente, mas em alguns casos, é necessário um novo tipo de conhecimento para que seja solucionado a necessidade. É aí que entra o papel do empreendedor e sua capacidade de estar conectado nas necessidades e as descobertas, para assim conseguir satisfazer um problema (DRUCKER, 2010)

Uma das características do empreendedorismo são as contradições que muitas vezes encontramos no seu processo. Muitas vezes uma oportunidade apresenta não ter potencial, mas se mostra um sucesso, como foi o caso dos microcomputadores desktop. Para prosperar é fundamental estar apto a enfrentar as ambiguidades que aparecem no ambiente (DORNELAS; SPINELLI; ADAMS, 2014).

Para Drucker (2010), uma empresa precisa ter em mente uma série de práticas necessárias para ser considerada empreendedora, e com isso estar melhor qualificada a atender a demanda e enfrentar a concorrência. A primeira é a aplicação de uma visão administrativa focada em oportunidades, a segunda é gerar um espírito empreendedor em todos os colaboradores, a terceira é a criação de reuniões informais com o intuito de um membro do alto escalão escutar as ideias, saber sobre oportunidades que os outros escalões verificam.

O que leva uma pessoa a entrar na seara do empreendedorismo muitas vezes é a busca por independência, tendo como segundo motivo a identificação de uma oportunidade. A busca por sanar uma necessidade, no caso financeira, é o terceiro maior fator de importância que leva alguém a empreender (VALE; CORRÊA; REIS, 2014).

\subsection{Estratégia organizacional}

O conceito de estratégia, segundo Bracker (1980) é derivado da palavra grega "strategos" "um general", que significam "exército" e "liderar". No centro da tradição militar de estratégia está a figura do general, presidindo do topo de uma rígida hierarquia. Sendo o general quem toma as decisões finais. Para Chandler (1962) estratégia é a determinação das metas e objetivos básicos e de longo prazo de uma empresa, e a adoção de ações e alocação de recursos necessários para atingir esses objetivos.

Em uma abordagem clássica da estratégia, Michael Porter (1980) afirma que estratégias competitivas são ações ofensivas ou defensivas para criar uma posição defensável em uma empresa, para enfrentar com sucesso as forças competitivas e assim obter um retorno maior sobre o investimento.

Porter (1986) destaca que a formulação da estratégia está baseada em cinco forças que determinam a dinâmica da competição em uma indústria: a) o poder de barganha dos clientes; b) o poder de barganha dos fornecedores; c) o setor competindo por uma posição entre os concorrentes existentes; d) a ameaça de produtos ou serviços substitutos; e) a ameaça de entrantes potenciais. A relação entre as 5 forças é demonstrada na figura 1. 


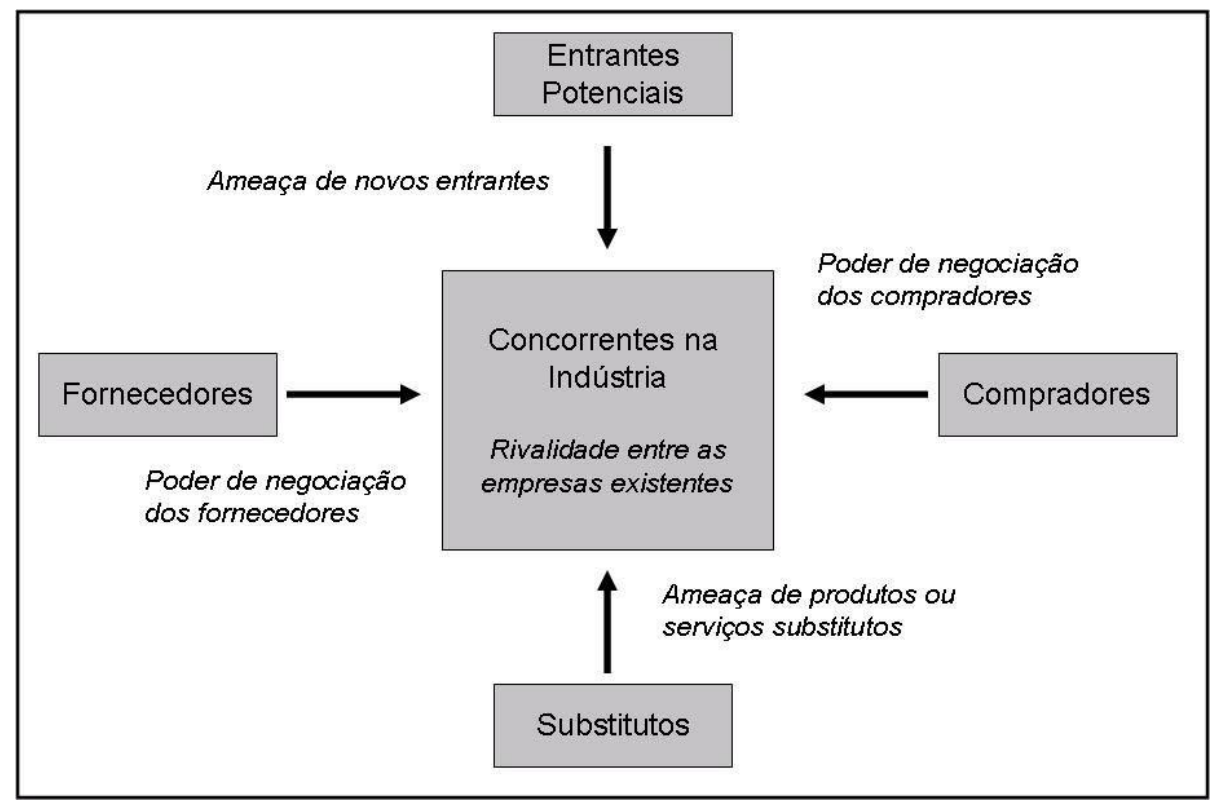

Figura 1. Cinco forças de Porter (1986).

Fonte: Porter (1986).

O autor ainda propõe que, para enfrentar essas cinco forças competitivas de cada segmento industrial, a empresa pode utilizar três abordagens diferentes para a estratégia de negócios: a) liderança em custos com fixação de preços agressiva e prejuízos iniciais para consolidar a parcela de mercado; b) diferenciação, através da busca das características únicas e exclusivas no produto ou serviço oferecido pela empresa. Esta estratégia também está associada à diferenciação pela qualidade; c) enfoque, atuando em determinado segmento de mercado. Esta estratégia tem como base a focalização no segmento específico: a empresa poderá competir tanto em termos de custo como em termos de diferenciação. A figura 2 demonstra as abordagens de Porter (1986).

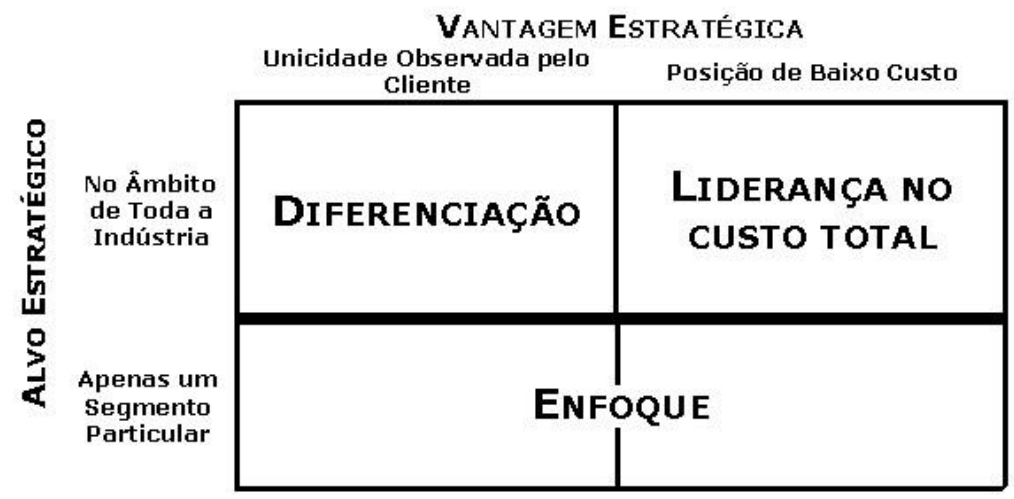

Figura 2. Estratégias competitivas de Porter (1986).

Fonte: Porter (1986)

\subsection{As diferentes formas de inovação}

Para acompanhar as mudanças as empresas têm procurado diferentes tipos de estratégias para acompanhar e se destacar de seus concorrentes e manter sua competitividade. Uma das estratégias mais utilizadas é a inovação, que é importante para a própria sobrevivência da organização e para gerar vantagem competitiva (CHESBROUGH, 2006). 
Pode-se definir inovação como um serviço ou produto iniciado por um processo interativo onde se visualiza uma oportunidade de sucesso comercial, que gerará valor para a empresa e sendo aceito pelos consumidores (OCDE, 1991 apud GARCIA; CALANTONE, 2002). Convém esclarecer que inovação não é uma estratégia restrita a grandes empresas ou de tecnologia, podendo ser usada em empresas de qualquer tamanho ou área de atuação, como em serviços (ZAWISLAK et al., 2013).

Dentro da realidade brasileira, a inovação ainda é influenciada drasticamente por uma estrutura vertical clássica, que não dá o suporte necessário para desenvolvimento de ações que facilitem o surgimento de ideias inovadoras (SEVERO, et al. 2012). A inovação depende muito de que sejam criadas condições para que ela floresça, desde interação entre pessoas para que possam se comunicar, aprender e ensinar, criando condições para a troca e geração de conhecimento (GUIMARÃES; SEVERO, 2015).

A inovação pode ser dividida em algumas categorias, com radicais e incrementais. As radicais, minoria dos casos, são assim chamadas por causar uma descontinuidade tecnológica ou de mercado e criação de novas tecnologias e mercados, além de novos concorrente e canais de distribuição. Pode-se classificar como inovações radicais a internet e os computadores pessoais. As inovações incrementais, consistem em melhorias realizadas em produtos e serviços (GARCIA; CALANTONE, 2002).

Dentro deste contexto, ainda existe a really new innovation que é a grande concentradora de inovações que existem no mercado. Este tipo de classificação de inovação é aquele em que a inovação apresentada é nova somente para a empresa, embora seja conhecida do mercado (GARCIA; CALANTONE, 2002).

Ainda na divisão dos tipos de inovação, pode-se ainda classifica-las como inovação fechada, que é quando a empresa cria, gera, desenvolve e comercializa sozinha suas ideias, e a inovação aberta, que prevê o uso de cooperação externa para desenvolvimento de seus produtos. Esta cooperação vem da compra de licenças de tecnologias e patentes, parceiras com outras empresas e instituições de pesquisas, fornecedores e usuário/clientes da empresa (CHESBROUGH, 2006).

\subsection{Marketing e desenvolvimento de produtos}

Las Casas (2007) descreve o conceito de marketing de acordo com a American Marketing Association, onde "Marketing é o processo de planejar e executar a concepção, estabelecimento de preços, promoção e distribuição de ideias, produtos e serviços a fim de criar trocas que satisfaçam metas individuais e organizacionais".

Entre os conceitos de marketing, destaca-se o mix de marketing, que são descritos por Kotler (2007) como o conjunto de ferramentas de marketing táticas e controláveis que a empresa combina para produzir a resposta que deseja no mercado-alvo. Consiste em tudo o que a empresa pode fazer para influenciar a demanda de seu produto. As diversas possibilidades podem ser agrupadas em quatro grupos de variáveis conhecidas como os 4 Ps propostos por Mc Carthy (1960), que são: Produto, Preço, Praça e Promoção (KOTLER, 2007).

Produto: é a combinação de bens e serviços que a oferece para o mercado alvo.

Preço: é a quantia de dinheiro que os clientes têm de pagar para obter o produto.

Praça: envolve as atividades que disponibilizam o produto aos consumidores alvo.

Promoção: envolve as atividades que comunicam os pontos fortes dos produtos e convencem os clientes-alvo a comprá-lo. 
Entre os 4 Ps, podemos destacar o "P" de Produto, que é o conjunto de atributos, funções e benefícios que os clientes compram, ou seja, é tudo o que pode ser oferecido ao mercado para a satisfação das necessidades e desejos dos consumidores.

As organizações orientam seus esforços de marketing de acordo com diferentes orientações, podendo ser orientadas para produção, para o produto, para vendas ou para marketing, conforme descrito por Kotler (2000):

Orientação para produção: sustenta que os consumidores dão preferência a produtos fáceis de encontrar e de baixo custo. Orientação de produto: os consumidores dão preferência a produtos que ofereçam qualidade e desempenho superiores ou que tenham características inovadoras. Orientação de vendas: Parte do princípio de que os consumidores e as empresas, por vontade própria, normalmente não compram os produtos da organização em quantidade suficiente. A organização deve, portanto, empreender um esforço agressivo de vendas e promoção. Orientação para marketing: Sustenta que a chave para alcançar as metas organizacionais está no fato de a empresa ser mais efetiva que a concorrência na criação, entrega e comunicação de valor para o cliente de seus mercados-alvo selecionados.

A Gestão de Portfólio de produtos busca a equalização dos projetos conduzidos pelas empresas, em termos da maximização de valor desses projetos, do alinhamento estratégico e dos tipos de projetos conduzidos. Para tal, é imprescindível a análise do conjunto de produtos em termos de dimensões mercadológicas, financeira e tecnológica, além da dimensão de recursos internos (COOPER et al., 1998).

De acordo com Kotler (2000), as ideias de novos produtos podem originar-se de muitas fontes - consumidores, cientistas, concorrentes, alta administração, etc. - porém, técnicas de criatividade (como o brainstorming), informações mercadológicas e técnicas de escolha entre ideias podem ser úteis para otimizar os resultados alcançados.

\section{MATERIAIS E MÉTODO}

Trata-se de uma pesquisa de natureza qualitativa, que leva em consideração os significados múltiplos das experiências individuais e proporciona a compreensão da linguagem, das percepções e dos valores das pessoas (YIN, 2010). Para atingir os objetivos propostos, será construído um Caso de Ensino, tendo como base fontes primárias, via entrevistas individuais com pessoas que atuam como informantes-chave dentro das organizações, combinadas com a observação direta do relator do caso (ROESCH, 2007).

Foi realizada uma entrevista semiestruturada com o gestor da empresa Expolight Metalúrgica Ltda, com o objetivo de conhecer a história da empresa para que seja possível analisar a situação e propor soluções para os problemas apresentados. A entrevista semiestruturada busca aumentar a familiaridade com o objeto de estudo e com os conceitos envolvidos, proporcionando insights sobre temas que não sejam de completo domínio do pesquisador (MALHOTRA, 2010).

A entrevista com o gestor foi efetuada na sede da empresa, em Passo Fundo - RS. A técnica utilizada para a coleta dos dados foi a entrevista semiestruturada em profundidade. A entrevista semiestruturada para a pesquisa qualitativa é um dos principais meios que tem o investigador para realizar a coleta de dados, pois ao mesmo tempo em que valoriza a presença do investigador, oferece todas as perspectivas possíveis para que o informante alcance a liberdade e espontaneidade necessárias, enriquecendo a investigação (YIN, 2010). Segundo Malhotra (2010), a entrevista individual em profundidade é utilizada quando um único respondente é testado por um entrevistador 
que busca encontrar respostas sobre crenças, atitudes e informações a respeito de um assunto. A entrevista foi complementada com informações do site oficial da empresa entrevistada.

\section{RESULTADOS E DISCUSSÕES}

Após a realização da entrevista com a empresa, foi possível estruturar um Caso de Ensino da Expolight expositores, empresa especializada em mobiliário corporativo e equipamentos para lojas. O caso será descrito contando a história da empresa, suas características e apresentando um ponto de decisão.

\subsection{Como tudo começou}

A Expolight é uma empresa que atua há mais de 15 anos na produção de móveis e expositores comerciais. É uma empresa familiar, administrada por três irmãos, onde todos participam das decisões da empresa. A família tem uma vocação empreendedora, já que o pai foi quem começou uma indústria metalúrgica em 1976. Com o passar do tempo a empresa foi crescendo e suas linhas de produtos foram se modificando. Tais mudanças culminaram com a criação de uma nova empresa especializada em mobiliário corporativo, que iniciou suas atividades em agosto de 1998, e que trouxe em seu DNA toda a experiência adquirida pelos filhos na empresa do pai.

Desde 2004 a empresa possui sede própria, instalada na região norte do Rio Grande do Sul, em uma área de $6.000 \mathrm{~m} 2$, sendo $3.500 \mathrm{~m} 2$ de área construída, onde encontram-se a administração, o setor de produção, o showroom e a expedição dos produtos. Atualmente a empresa conta com mais de 70 colaboradores.

O modelo do negócio é baseado na produção própria de produtos elaborados em metal e MDF, comercialização, entrega e montagem dos produtos diretamente para o cliente, que são os varejistas.

Os principais produtos são móveis planejados para lojas e escritórios, ou seja, as instalações do ponto de venda, e o seu público-alvo são redes de lojas, empresas que necessitam de produtos diferenciados e empresas em expansão. Podemos identificar segmentos distintos como Supermercados, Lojas de Confecções e Calçados, Materiais de Construção e Ferragens, Farmácias, Perfumarias, Eletroeletrônicos, Lojas de conveniência, Bazar e livrarias, Indústrias em geral (displays), escritórios em geral, entre outros.

Em seu planejamento estratégico, a Expolight buscava ser reconhecida pela excelência de seus produtos e serviços, oferecendo a seus clientes soluções completas para os diversos segmentos em que atua, buscando sempre a inovação e visando ter parcerias sólidas com seus clientes.

A empresa busca oferecer um projeto personalizado, com agilidade e diversas opções de configuração e acabamentos, facilitando a visualização do ambiente e a escolha da melhor opção de mobiliário. A maneira proposta para melhor atender o cliente é através de vendedores e representantes em regiões próximas ao público alvo, oferecendo o projeto, assessoria, consultoria e a montagem do mobiliário, seguindo as mais modernas tendências do varejo.

Os principais concorrentes são as lojas de revenda (que vendem móveis de baixo custo), Fornecedores dos varejistas (que fornecem displays junto com a mercadoria), Empresas de mesmo porte com produtos semelhantes, Empresas de grande porte e indústrias multinacionais. O número de concorrentes é grande, porém poucas empresas oferecem a solução completa com o projeto, móveis em metal, móveis em MDF, montagem dos equipamentos e comunicação visual aplicada no mobiliário. O preço muitas vezes não é o ponto mais importante na negociação. Em muitos casos, as indústrias que fornecem displays para os seus clientes também podem ser clientes da Expolight. 


\subsection{O crescimento do empreendimento}

Através de sua estratégia de oferecer produtos diferenciados e adequados às necessidades dos lojistas, a Expolight conseguiu ter clientes em nível nacional, sendo os principais segmentos as redes de farmácias e as redes de lojas de móveis e eletro.

A empresa tem uma linha de produtos padronizada, com diversas variações tanto nas medidas como em acabamentos e trabalha com um sistema de customização, fazendo projetos onde os móveis se adaptam as necessidades dos clientes.

Observando o crescimento do mercado, a Expolight preocupou-se em evoluir, criando novas linhas de produtos e investindo em equipamentos para produção e em softwares de projeto, tornando os móveis planejados para lojas seu principal produto. Em função do software exclusivo desenvolvido para a elaboração dos projetos, a empresa passou a ter mais agilidade e qualidade nos projetos apresentados aos clientes, sendo a primeira empresa do setor a contar com esta ferramenta de vendas no ramo de móveis comerciais.

Os clientes de maior expressão, normalmente exigem um maior grau de personalização, fazendo com que a empresa adapte alguns produtos para torná-los adequados as exigências dos grandes clientes. Esta flexibilização dos produtos auxiliou a empresa a captar novos clientes, com exigências cada vez maiores quanto a qualidade dos produtos e serviços.

Em função destes produtos personalizados, em muitas ocasiões faz-se necessário a confecção de amostras ou protótipos dos produtos para que sejam avaliados e aprovados. Os protótipos depois de aprovados são utilizados nas entregas que serão feitas depois que as encomendas forem feitas.

A fabricação de protótipos começou a ficar comum no dia a dia da empresa, porém em alguns casos, as encomendas não eram feitas pelos clientes. Os motivos são diversos, entre eles a concorrência com outras empresas que também se dispõem a fazer amostras sem garantia de compra e também as mudanças de planos das grandes redes de varejo.

Dificilmente a empresa consegue cobrar pelo protótipo, em caso de a empresa não fechar o pedido. Porém se a empresa não fabricar estas amostras, mesmo sem a garantia de que vai poder vender o produto, a empresa fica fora da concorrência de clientes potenciais.

$\mathrm{O}$ alto custo de investimento nas amostras, que giravam em torno de $\mathrm{R} \$ 5$ mil por cliente, e que muitas vezes não se tornavam pedidos, começaram a ser questionadas pela direção da empresa. Havia um entendimento de que os protótipos eram ferramentas importantes para o negócio, porém deveriam ser analisados com mais critério, para que os riscos de a negociação não dar certo e a empresa ter que arcar com um prejuízo tanto de materiais como de mão de obra, sejam minimizados.

Além disso, a empresa havia feito investimentos para o crescimento das linhas de produtos padronizados, permitindo a customização dos mesmos, aumentando a produtividade da fábrica e também o volume de vendas através dessa estratégia de padronização e customização, sendo que no ano de 2010 houve um aumento de $23 \%$ no faturamento da empresa em relação ao ano anterior, como mostra a figura 3. 


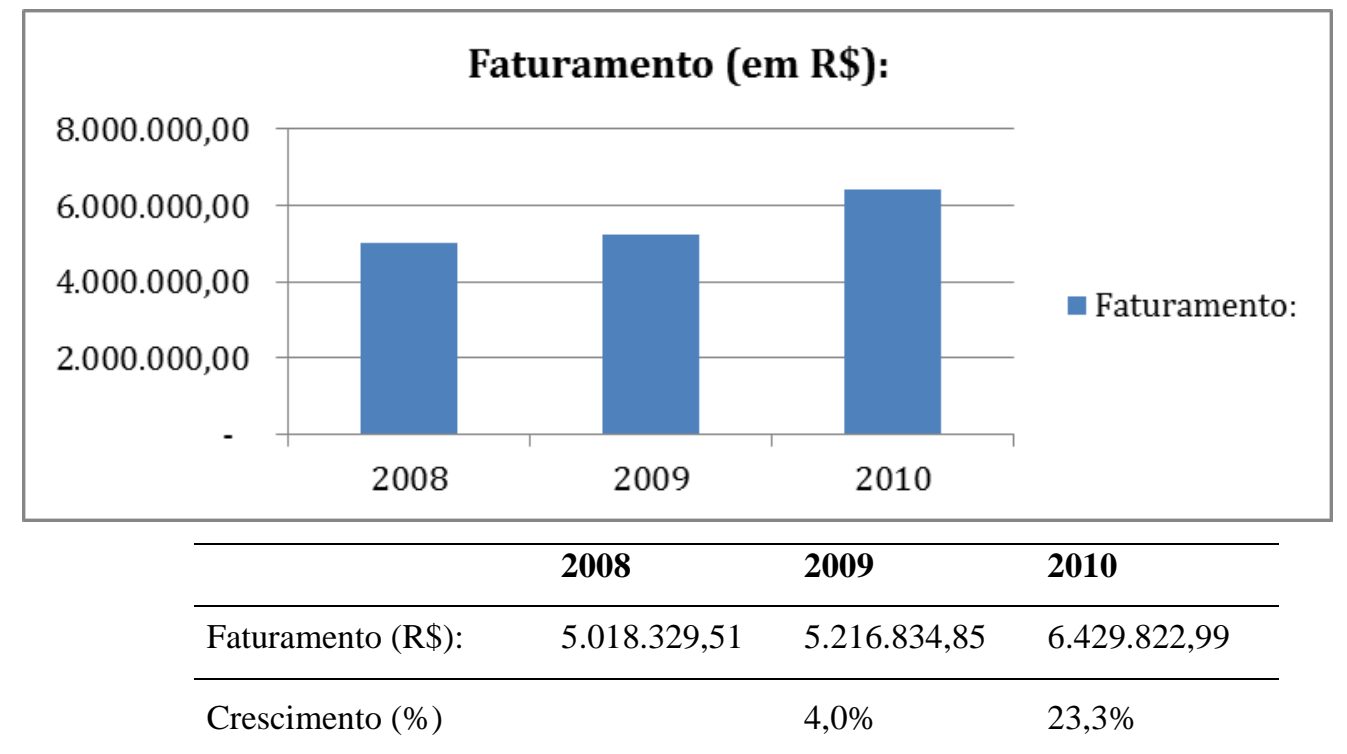

Figura 3. Faturamento da empresa entre 2008 e 2010.

Fonte: Expolight Metalúrgica Ltda

\subsection{A decisão a ser tomada}

O crescimento do PIB em 2010 foi de 7,6\%, e havia a expectativa mundial que ele continuaria a crescer no mesmo ritmo. Paralelo a isso, nos países da Europa, naquele ano começaram vários protestos contra os pacotes de arrocho para enfrentar a crise. A economia era a grande vilã, por conta do nervosismo nos mercados, com o dólar desvalorizado e o futuro incerto do euro.

O cenário econômico começava a dar os primeiros sinais de que a economia não conseguiria crescer no mesmo ritmo do ano anterior, apesar do crescimento observado, enquanto na Europa a situação era caótica, com vários países passando por problemas econômicos graves, chegando a atingir os EUA, maior economia do mundo. Para salvar o Euro, Alemanha e França se aliam e criam pacotes para o desenvolvimento da zona do euro.

No primeiro trimestre de 2011, a economia brasileira cresceu 4,2 \% em relação ao mesmo período do ano anterior, colocando o país em $4^{\circ}$ lugar em crescimento dentro do BRICS (Brasil, Rússia, Índia, China e África do Sul) atraindo atenção de muitas empresas internacionais.

Nesse contexto em maio de 2011 surgiu uma oportunidade de negócio com uma empresa multinacional do ramo de cosméticos, que decidiu iniciar suas operações no Brasil e buscava parceiros para suprir suas necessidades, entre elas o mobiliário.

Essa empresa entrou em contato com a Expolight e foram iniciadas as negociações, com diversas etapas. Primeiro uma avaliação para verificar se havia interesse em produzir o mobiliário proposto. Para isso foi preciso assinar um termo de confidencialidade tanto em relação aos projetos de móveis quanto a divulgação da vinda dessa empresa para o Brasil.

A segunda etapa foi a parte orçamentária, onde com base nos projetos apresentados foram feitos orçamentos preliminares, já que não haviam muitos detalhes técnicos nos projetos. A empresa foi aprovada nesta etapa e chegou a fase de avaliação do produto.

A condição para a empresa ser aprovado incluía a confecção de uma série de móveis, que eram totalmente diferentes do que a empresa costumava produzir. Seria necessário investimento em equipamentos, terceirizar uma série de serviços, trabalhar com materiais diferenciados como acrílico, iluminação com Led, tintas especiais, fixação através de componentes magnéticos (ímãs), 
etc. Estes protótipos ainda passariam pela avaliação de uma equipe de técnicos Norte Americanos, que viriam até o Brasil para validar os produtos.

Além disso, devido às informações técnicas não serem completas, foi sugerido uma visita a uma loja para servir como modelo, onde poderiam ser esclarecidas todas as dúvidas em relação ao material empregado, medidas exatas para a fabricação dos protótipos, os acabamentos, cores, assessórios, entre outras dúvidas que poderiam surgir sobre o mobiliário.

A loja indicada localizava-se na Cidade do México, no México, o que implicaria em uma viagem até este país para fazer a visita nesta loja. Esta viagem iria consumir pelo menos uma semana de envolvimento de duas pessoas de nível gerencial, além dos elevados custos da viagem, considerando que não havia muito tempo para adquirir passagens, providenciar passaportes e reservar hotéis. Os custos estimados entre equipamentos, ferramental, materiais, mão de obra e viagens ultrapassariam o valor de $\mathrm{R} \$ 100 \mathrm{mil}$.

Nesse contexto, a empresa precisa decidir se aceita participar desta fase da concorrência, considerando o investimento em viagens, fabricação de protótipos, aquisição de equipamentos e o tempo necessário para o projeto; ou se a empresa abre mão desta concorrência e utiliza estes recursos em atividades que são mais familiares à empresa e que apresentam menor risco, como é o caso dos produtos padronizados no qual a empresa já fez algum investimento. A direção da empresa decidiu convocar uma reunião para analisar as possibilidades, escutar a opinião de cada setor envolvido e obter subsídios para tomar a melhor decisão em relação ao problema apresentado.

Na reunião, o gerente comercial foi o primeiro a expor seu ponto de vista:

- A parceria com esta multinacional, apesar dos riscos envolvidos, fará com que a empresa eleve seu patamar tanto em relação a produtos como em relação a clientes, abrindo novas possibilidades de negociações com empresas de maior porte e multinacionais, além é claro do contrato que a empresa proporcionaria, que representaria um acréscimo de $\mathrm{R} \$ 1$ milhão por ano na receita da empresa, sendo que a parceria seria para um período estimado de cinco anos, no caso de ser aprovada neste processo.

O gerente de produção apresentou um contraponto:

- Abrindo mão dessa negociação, a empresa conseguirá manter seu foco em produtos padronizados, reduzindo os custos de produção e concentrando seus esforços em conquistar clientes que demandem seus produtos, sem a necessidade de ter que se adaptar a cada situação específica. A ideia seria aumentar a linha de produtos padronizados, com opções de customização, oferecendo projetos diferenciados com produtos modulados.

A responsável pelas finanças da empresa decidiu participar da discussão:

- Os investimentos são altos e existe o risco de o cliente não aprovar o projeto. Como já foram feitos investimentos em novas linhas de produtos, acredito que não seria o momento oportuno para encarar este desafio. Por outro lado, é uma grande oportunidade, levando em consideração o faturamento que a empresa pode obter, tendo em vista ainda que a margem de contribuição da negociação é atrativa.

Antes de tomar qualquer decisão, o diretor da empresa profere as seguintes palavras:

- Todos concordamos que é uma decisão importante a ser tomada. Esta decisão implica em manter ou alterar nosso posicionamento estratégico. Precisamos decidir o que faremos, se a empresa deve adequar-se as exigências da contratante e fazer os investimentos e mudanças necessárias, ou optar em não continuar neste processo e dar sequência ao plano que já está em andamento, de investir em novas linhas de produtos customizados. 
O futuro da empresa está em jogo e a questão é: Qual a melhor decisão a ser tomada?

\subsection{Notas de ensino}

Este Caso de Ensino foi elaborado para aplicação em cursos de graduação e pós-graduação, nas disciplinas de empreendedorismo, administração estratégica, gestão da inovação e Marketing. Em relação a decisão a ser tomada, a organização pode optar em adotar as seguintes opções:

Adequar-se as exigências da contratante

Não adequar-se.

\subsubsection{Objetivos de aprendizagem}

Com a análise do caso da empresa Expolight Expositores será possível abordar e refletir alguns temas relativos ao processo de ensino/aprendizagem em administração, entre estes:

a) Discussões sobre empreendedorismo, riscos e oportunidades;

b) Estudos sobre as características de empreendedorismo;

c) Estudo das alternativas de estratégias, avaliando os recursos necessários para implementálas, bem como as vantagens e desvantagens da adoção dessas alternativas;

d) Estudo da estratégia baseado nas cinco forças de Porter;

e) Decisões em relação ao posicionamento da empresa no mercado, utilizando as estratégias competitivas de Porter;

f) Discussões sobre as diferentes formas de inovação;

g) Estudos sobre orientação da empresa para produção, produto, vendas ou marketing.

h) Estudos sobre desenvolvimento de produtos. A influência do cliente nas decisões de novos produtos.

\subsubsection{Sugestões de questionamentos para discussão em sala de aula}

1) Com base nas informações relatadas no caso e na literatura, qual a decisão estratégica a empresa deve tomar? Aceitar as exigências do cliente e assumir riscos buscando uma nova posição para a empresa, ou manter o plano de crescimento baseado em sua linha própria de produtos? Justifique a resposta.

2) Quais características empreendedoras podem ser identificadas no caso?

3) Segundo Garcia e Calantone (2012), existem diferentes formas de inovação. Quais os tipos de inovação poderão ser considerados conforme a decisão que a empresa irá tomar?

4) Qual o posicionamento estratégico da empresa, segundo Porter (1980) Liderança em custo, Diferenciação ou Foco? Conforme a decisão da empresa, este posicionamento continua o mesmo ou se modifica?

5) O produto, que compõe o mix de marketing (KOTLER, 2000), é fundamental para o sucesso das organizações. Qual a influência do cliente na decisão quanto ao desenvolvimento de produtos?

6) Um dos fatores que influenciam a decisão da empresa é referente adequação dos produtos para um novo mercado. Segundo Kotler (2000), as empresas são orientadas para produção, produtos, vendas ou marketing. Neste caso, qual a orientação da empresa? Esta orientação se altera de acordo com a decisão tomada? 
7) A decisão a ser tomada leva em consideração o contexto de 2011, no caso de utilizar o contexto atual, qual seria a melhor decisão a ser tomada? Esta decisão seria diferente? Justifique a resposta.

\section{CONSIDERAÇÕES FINAIS}

O Caso de Ensino é uma importante ferramenta para o ensino, aliando a teoria à prática. Os principais objetivos de um caso para ensino são desenvolver conhecimentos, habilidades e atitudes consideradas chaves para o sucesso gerencial, familiarizar os estudantes com as organizações e seu ambiente e ilustrar aulas expositivas (ROESCH, 2007).

Este artigo teve como objetivo promover discussões e reflexões sobre temas como empreendedorismo, administração estratégica, gestão da inovação e Marketing, exercitando a tomada de decisão, utilizando o caso da empresa estudada e os conhecimentos apresentados na revisão bibliográfica. Para isso, foi realizada uma entrevista em uma empresa de móveis com o intuito de identificar uma situação onde foi necessária uma tomada de decisão.

Através das diversas possibilidades de análise do caso, tendo em vista o exercício da tomada de decisão e a aplicação dos conhecimentos teóricos, percebe-se como este Caso de Ensino pode auxiliar no ensino de alunos de cursos de graduação e pós-graduação, contribuindo de forma significativa para o aprendizado do público a que se destina, principalmente no estudo da gestão.

Dessa forma, este Caso de Ensino pode ser aplicado em diversos cursos de graduação e pósgraduação, nas disciplinas propostas ou em outras que possam ser úteis. O caso pode ser aplicado em sala de aula, como complemento de aulas expositivas, como trabalho em grupo, como leitura complementar ou como um trabalho a ser desenvolvido durante o aprendizado.

\section{REFERENCIAS}

BRACKER, J. The historical development of the strategic management concept. Academy of management review, v. 5, n. 2, p. 219-224, 1980.

CHANDLER, A. Strategy and Structure, MIT Press, Cambrige, 1962.

CHESBROUGH, H. W. The era of open innovation. In: MAYLE, David. Managing Innovation and Change. 3. ed. London: Sage, 2006. Cap. 11. p. 127-138.

COOPER, R. G.; EDGETT, S. J.; KLEINSCHMIDT, E. J. Best practices for managing R\&D portfolios. Research technology management, v. 41, n. 4, p. 20, 1998.

DORNELAS, J. C. A. Empreendedorismo: transformando ideias em negócios. 2. ed. Rio de Janeiro: Elsevier, 2005. $232 \mathrm{p}$.

DORNELAS, J.; SPINELLI, S.; ADAMS, R. Criação de novos negócios: empreendedorismo para o século XXI. 2. ed. São Paulo: Elsevier, 2014.

DRUCKER, P. F. Inovação e espírito empreendedor: práticas e princípios. São Paulo: Cengage Learning, 2010. 378 p.

GARCIA, R.; CALANTONE, R. A critical look at technological innovation typology and innovativeness terminology: a literature review. The Journal Of Product Innovation Management, S.i., v. 19, n. 2, p.110-132, mar. 2002.

Guimarẽes, J. C. F., SEVEro E. A., ROESCH, S. M. A., OlEA, P. M., DORION, E. C. H. Crescimento ou manutenção da posição: o dilema dos gestores de uma indústria de plásticos da serra gaúcha. Redes, v. 18, n. 3, p. 157$175,2013$.

GUIMARÃES, J. C. F. de; SEVERO, E. A.; SENNA, P. A relação entre inovação e a vantagem competitiva sustentável: trajetória e desafios. Espacios, S.i., v. 36, n. 12, p.1-1, jun. 2015.

GUIMARÃES, J. C. F.; SEVERO, E. A.; PEREIRA, A. A.; DORION, E. Inovação no processo e melhoria contínua em uma indústria de plásticos do polo moveleiro da Serra Gaúcha. In: CONGRESSO NACIONAL DE EXCELÊNCIA EM 
GESTÃo - CNEG, VIII, 2011, Rio de Janeiro. Anais do VIII Congresso Nacional de Excelência em Gestão. Rio de Janeiro, 2007.

KOTLER, P. Marketing para o Século XXI. Futura, 2000.

KOTLER, P.; ARMSTRONG, G. Princípios de marketing. In: Princípios de marketing. Pearson Prentice Hall, 2007.

LAS CASAS, A. L.; GARCIA, T. M. Estratégias de Marketing para Varejo. Inovações e Diferenciações Estratégicas que Fazem a Diferença no Marketing de Varejo. São Paulo: Novatec, 2007.

MACHADO, A. G. C.; MORAES, W. F. de A. Estratégias de customização em massa implementadas por empresas brasileiras. Revista Produção, v. 18, n. 1, p. 170-183, 2008.

MALHOTRA, N. K. Marketing research: An applied orientation. New Jersey: Pearson Education, 2010.

MOVERGS - Associação das Industrias de Moveis do Rio Grande do Sul. Disponível em: <http://www.movergs.com.br>. Acesso em: 10 jun. de 2012.

POLIGNANO, L. A. C.; DRUMOND, F. B. O papel da pesquisa de mercado durante o desenvolvimento de produtos.

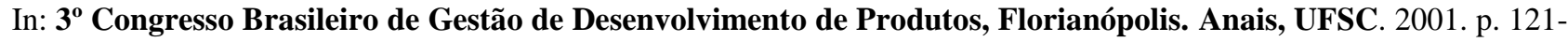
130 .

PORTER, M. E. Competition in global industries. Harvard Business Press, 1986.

PORTER, M. E. Competitive strategy: Techniques for analyzing industries and competition. New York, p. $300,1980$.

ROESCH, S. M. A. Notas sobre a construção de casos para ensino. Revista de Administração Contemporânea, v. 11, n. 2, p. 213-234, 2007.

SALIM, C. S.; NASAGON, C.; SALIM, H.; MARIANO, S. Administração empreendedora. 4. ed. São Paulo: Elsevier, 2004.

SEVERO, E. A.; CRUZ, M. R. da; DORION, E.; GUIMARÃES, J. C. F. de; PEREIRA, A. A. Estrutura organizacional das empresas inovadoras no Brasil. 2012. Disponível em: <http://www.revistaespacios.com/a12v33n11/12331105.html>. Acesso em: 10 set. 2014.

VALE, G. M. V.; CORRÊA, V. S.; REIS, R. F. dos. Motivações para o empreendedorismo: necessidade versus oportunidade? Rev. Adm. Contemp., [s.1.], v. 18, n. 3, p.311-327, maio 2014.

YIN, R. K. Qualitative research from start to finish. Guilford Press, 2010. 